\section{Sensors for Improved Efficiency of Irrigation in Greenhouse and Nursery Production}

\author{
Marc W. van Iersel ${ }^{1,3}$, Matthew Chappell ${ }^{1}$, and John D. Lea-Cox ${ }^{2}$
}

ADDITIONAL INDEX WORDs. evapotranspiration, light, modeling, relative humidity, remote sensing, soil moisture, soilless substrate, temperature, vapor pressure deficit, water, wind

\begin{abstract}
SUMmARY. The use of sensors can provide quantitative information to help guide and automate the decision-making process for irrigation. This article provides an overview of the most common sensors that can be used for this purpose. Such sensors include those that are commonly used for weather stations as well as sensors to monitor the water status of the soil or substrate, and sensors that can be used to monitor and troubleshoot irrigation systems. Although collecting data with sensors is relatively easy, data are only useful if the sensors are used correctly and the limitations of sensors are understood. Optimizing the value of the collected data requires selecting the best sensor(s) for a particular purpose, determining the optimal number of sensors to be deployed, and assuring that collected data are as accurate and precise as possible. We describe general sensing principles and how these principles can be applied to a variety of sensors. Based on our experience, proper use of sensors can result in large increases in irrigation efficiency and improve the profitability of ornamental production in greenhouses and nurseries.
\end{abstract}

A lthough irrigation control in ornamental production is commonly achieved with timers and/or with the experiential judgment of an irrigation manager, such methods are unlikely to provide water when needed and in the amount required by the crop. Sensor networks and water use models have been suggested as ways to improve irrigation efficiency and reduce water use in ornamental horticulture (Lea-Cox, 2012; Million et al., 2010). Using sensors to collect quantitative information about crop water requirements can provide objective information to improve irrigation management. Sensing environmental and soil/substrate conditions is becoming easier and economically feasible, providing opportunities to integrate such sensors into existing irrigation systems. Accurate, quantitative information of environmental conditions (e.g., weather, soil/substrate water status) can be used to help guide decision making

This paper is part of a series of manuscripts describing the research and development completed by the SCRI-MINDS (Managing Irrigation and Nutrition through Distributed Sensing) project. The authors gratefully acknowledge funding and support from the USDA-NIFA Specialty Crops Research Initiative; Award \#2009-51181-05768.

${ }^{1}$ Department of Horticulture, University of Georgia, Athens, GA 30602

${ }^{2}$ Department of Plant Science and Landscape Architecture, University of Maryland, College Park, MD 20742

${ }^{3}$ Corresponding author. E-mail: mvanier@uga.edu. pertaining to 1 ) when to irrigate and 2) how much water to apply, to increase irrigation efficiency and reduce runoff. However, simply collecting data may not be adequate; those data then need to be converted to usable information, allowing growers to make decisions based on that information. Thus, user-friendly software that presents summary information in an easyto-interpret format is at least as important as the hardware. Here, we focus on available sensors for use in irrigation control systems. Other articles in this series (Kohanbash et al., 2013) discuss the hardware to measure and collect the data, software to present the data in a user-friendly, actionable format, the use of sensor networks for automated, precision irrigation management (Belayneh et al., 2013; Chappell et al., 2013), and the economic impact wireless sensor networks can have (Belayneh et al., 2013; Lichtenberg et al., 2013).
There are various ways in which sensor data can be used to help make irrigation decisions. The simplest method is to turn irrigation on and off based on whether a particular sensor reading is below or above a user-defined threshold. For example, irrigation can be turned on and off based on the amount of water present in the soil/substrate or based on a measure that is an indicator of plant drought stress. More complex approaches may involve the modeling of crop water use or evapotranspiration (ET) based on weather conditions and crop-specific factors (e.g., Bauerle et al., 2002; Bauerle and Bowden, 2011; Beeson, 2010; Million et al., 2010).

Although there are different ways to estimate ET from weather conditions, the most common approach is the Food and Agriculture Organization (FAO) Penman-Monteith method, which uses commonly measured weather data [net radiation, temperature, relative humidity $(\mathrm{RH})$, wind, and rainfall] to calculate a reference $\mathrm{ET}$ value $\left[\mathrm{ET}_{0}\right.$ in millimeters or inches per day (Allen et al., 1998)]. The $\mathrm{ET}_{0}$ is calculated based on an energy balance model and estimates the ET from an extensive surface of green grass with a height of $120 \mathrm{~mm}$. This $\mathrm{ET}_{0}$ is then multiplied by a crop coefficient $\left(K_{c}\right)$ to calculate the expected ET for a particular crop. Crop coefficients depend on the species, the size of the crop, and change over time.

Determining crop coefficients for ornamental species is complicated. There are too many ornamental species to determine crop coefficients for all of them, and even within species there may be substantial differences in growth characteristics among cultivars. Because crops may not exhibit the same growth pattern each year, crop coefficients for a specific crop may differ from year to year (O'Meara et al., 2013). Beeson (2012) showed

\begin{tabular}{llll}
\hline $\begin{array}{l}\text { Units } \\
\begin{array}{l}\text { To convert U.S. to SI, } \\
\text { multiply by }\end{array}\end{array}$ & U.S. unit & SI unit & $\begin{array}{l}\text { To convert SI to U.S., } \\
\text { multiply by }\end{array}$ \\
\hline 10.7639 & $\mathrm{fc}$ & $\mathrm{lx}$ & 0.0929 \\
0.0283 & $\mathrm{ft}^{3}$ & $\mathrm{~m}^{3}$ & 35.3147 \\
2.54 & inch(es) & $\mathrm{cm}$ & 0.3937 \\
25.4 & inch $(\mathrm{es})$ & $\mathrm{mm}$ & 0.0394 \\
0.1 & $\mathrm{mbar}$ & $\mathrm{kPa}$ & 10 \\
1 & $\mathrm{mmho} / \mathrm{cm}$ & $\mathrm{dS} \cdot \mathrm{m}^{-1}$ & 1 \\
1 & $\mathrm{mmho} / \mathrm{cm}$ & $\mathrm{mS} \cdot \mathrm{cm}^{-1}$ & 1 \\
28.3495 & $\mathrm{oz}$ & $\mathrm{g}$ & 0.0353 \\
1 & $\mathrm{ppm}$ & $\mathrm{mg} \cdot \mathrm{L}^{-1}$ & 1 \\
$\left({ }^{\circ} \mathrm{F}-32\right) \div 1.8$ & ${ }^{\circ} \mathrm{F}$ & ${ }^{\circ} \mathrm{C}$ & $\left({ }^{\circ} \mathrm{C} \times 1.8\right)+32$
\end{tabular}


that canopy closure can be used as a proxy for $K_{c}$. Canopy closure measurements can be automated using digital cameras and image processing software (Klassen et al., 2003). Alternatively, canopy size could be estimated based on canopy light interception, using light sensors above and below the canopy (Lampinen et al., 2012) or normalized difference vegetation index measurements (McClymont et al., 2012). Such measurements are easily automated and can be integrated into sensor networks. Note that the ET estimates developed from $\mathrm{ET}_{0}$ values and $K_{\mathrm{c}}$ assume that the crop has access to unlimited water resources. Adjustments would be required if water availability is limited by drought or salinity (Allen et al., 1998).

There is no general agreement whether it is better to control irrigation using sensor readings of the soil/ substrate water status, plant water status, or based on model predictions of ET. Different applications may require different solutions and hybrid or combined approaches may be optimal in many cases. Evapotranspiration modeling generally works well for large-scale, agronomic monocropping systems or turfgrass, but is more difficult to apply in greenhouses, nurseries, or both with a large variety of species and cultivars or in situations where accurate $K_{\mathrm{c}}$ values may not be available. Another option is the combined use of sensors and models, where irrigation could be controlled using models, while sensors are used to assure the plants do receive adequate water (or vice versa). Scheduling irrigation in greenhouses and nurseries is especially challenging because different crops may be grown together in a single irrigation zone. In such cases, the best approach may be to estimate the water needs of the crop that requires the most water and overirrigating the other crops.

Our objective is to provide a general overview of sensing principles and a variety of sensors that can be incorporated into automated irrigation control systems, with an emphasis on weather data, soil/substrate water, and methods to monitor irrigation systems. As a result of space limitations, this is not intended to be a complete review of these topics. Whenever appropriate, readers are referred to more in-depth reviews.

\section{General sensing principles Measurement errors}

A sensor can be defined as any instrument that measures some type of physical or chemical characteristic and converts that measurement into a signal that can be read by an observer or automated data collection system. All sensors have measurement errors and it is important to understand the different limitations that affect measurements. There are three important sources of measurement error (Fig. 1): 1) accuracy-how close is the measured value to the true value of the characteristic being measured?; 2) repeatability (also called precision) how similar are the measurements if the same property, in a static state, is measured multiple times?; and 3 ) resolution-what is the smallest change in the physical characteristic that can be detected by the sensor? The ideal sensor would combine great accuracy with good repeatability and high resolution, but in many cases, increased sensor performance also increases the price. Therefore, it is important to consider what minimum specifications a sensor needs to have to be useful for a particular purpose. For example, a soil moisture sensor used for research purposes needs to be accurate, have good repeatability, and needs to have adequate resolution. However, a soil moisture sensor that is used for irrigation control purposes does not necessarily have to have the same accuracy, as long as the readings are repeatable and have adequate resolution. If the sensor can reliably detect changes in soil/substrate water content, the sensor can be used for irrigation control, even if the readings are not accurate.

Manufacturer specifications often do not clearly distinguish between accuracy, repeatability, and resolution, making it difficult to predict sensor performance based on those specifications. In most cases, sensor resolution is not critical, since most sensors have better resolution than repeatability, in which case the high resolution does not provide any useful information.

To optimize the value of information from sensor measurements, end users need to think about the required data accuracy and the various ways in which this can be improved. This includes proper calibration of the sensors, determining how often data should be collected and/or averaged,

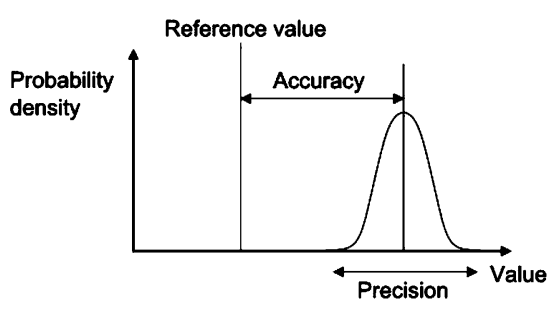

Fig. 1. Graphical presentation of the difference between accuracy (how close is the measured value to the "true" or reference value) and precision (or repeatability; how similar are the measured values if the same property is measured multiple times). Image courtesy of Pekaje (Wikipedia, 2013).

and the number of sensors that should be used.

Calibration. Sensor accuracy can be assured or improved with careful and timely calibration, preferably against a National Institute of Standards and Technology-traceable standard. Note that sensor accuracy typically changes over time, while repeatability and resolution do not. The rate at which the accuracy changes determines how often the sensor needs to be recalibrated.

FREQUENCY OF DATA COLLECTION AND AVERAGING. It is important to consider the optimal frequency of data collection, which depends on the repeatability of the sensor, as well as the properties of the environment being sensed. Repeatability can be improved by collecting data more frequently and using a running average of the collected data for subsequent analysis and decision making. Although more frequent measurements do not improve the performance of the sensor itself, averaging multiple measurements can remove much of the noise (apparently random, unwanted variation) that could otherwise be present in the data. If data are collected and averaged automatically, a high sampling frequency is a feasible option. Resolution may also be improved by collecting data more frequently and averaging those data. The optimal sampling frequency also depends on how dynamic the changes to be measured are, for example, substrate water content of large plants in relatively small containers should be measured more often than soil water content of small plants grown under field conditions. 
Using MUlTIPLE SENSORS. The quality of the collected data can often be improved by using multiple sensors, but this also increases the cost of data collection. Determining the optimal number of sensors to be used is difficult since it depends on the accuracy and repeatability of the sensor, variation among sensors, spatial environmental variation, the cost of installing multiple sensors, and the value of the additional information that can be gained from using more sensors. It can be beneficial to initially densely sense an environment. Once the major sources of variability have been identified, this information can be used to determine the optimal number and placement of fewer sensors. Identifying sensor-to-sensor variability in a particular environment greatly increases confidence in the data. For example, variability in soil moisture sensor readings in green roofs changes over time [Fig. 2A (Starry, 2013)]. Much of this variability among different sensors could be explained by changes in substrate volumetric water content (VWC); when the substrate was dry, uniformity among the sensors was good, indicating that the substrate was uniformly dry (Fig. 2B). The greatest variability among sensor readings occurred at VWC levels just below the water-holding capacity of the substrate. Presumably, heavy rain brought the substrate back to its water-holding capacity, resulting in uniform wetting. Subsequent plant water uptake presumably was preferentially from parts of the substrate with high root density, increasing spatial variability of substrate VWC (Fig. 2B). For an example of how to determine the optimum number of samples, see Daniels et al. (2012). They discuss the number of sensors needed to get accurate substrate VWC measurements for 10 containerized tree species and conclude that optimal numbers of sensors may be specific to species and root density. Bauerle et al. (2013) discuss how root distribution in containers can affect the variability in VWC measurements.

Other sensor characteristics that should be considered when selecting a sensor for a specific purpose include sensor range (what are the lower and upper bounds being measured), response time (how quickly does the sensor respond to a change in the physical characteristic being measured), and hysteresis (the influence of previous conditions on the current measurement) (Strangeways, 2003).

In addition to taking into account the limitations of the sensors themselves, it is also important to deploy sensors to optimize the information gained from the environment in which the sensors are placed. Careful consideration of sensor calibration, placement and number of sensors required in any particular situation not only optimizes the cost of sensor networks but increases the value of the data from that environment or situation. Ultimately, trusting the information gained from the sensors is the key to optimizing the cost and perfecting the decisions made with sensor network(s). For an in-depth review of general measurement theory, see Hand (2010). Hubbard and Hollinger (2005) and Strangeways (2003) discuss measurement principles directly related to weather, micrometeorological, or both applications.

\section{Sensing weather conditions}

Weather conditions play a large role in determining the water use of crops, and resulting irrigation requirements. In many cases, weather data are available from nearby weather stations, in which case an on-site weather station may not be necessary. However, when using weather data from an offsite weather station, it is important to verify that the information from that station is accurate enough for use at the site of interest. Microclimatic differences are common, and as a result, there can be significant differences in weather conditions among sites that are close together. The weather parameter that is perhaps most variable across relatively small distances is rainfall, particularly in summer months.

Light. Light, or solar radiation, is probably the most important environmental variable affecting water use of ornamental plants (e.g., Baille et al, 1994; Bayer et al., 2013; Löfkvist et al., 2009; O'Meara et al., 2013). There are two common ways to measure light that are relevant to plants: 1 ) the total energy of the incoming light (shortwave radiation) and 2) photosynthetically active radiation $(P A R)$. The difference between these two measures is that shortwave radiation
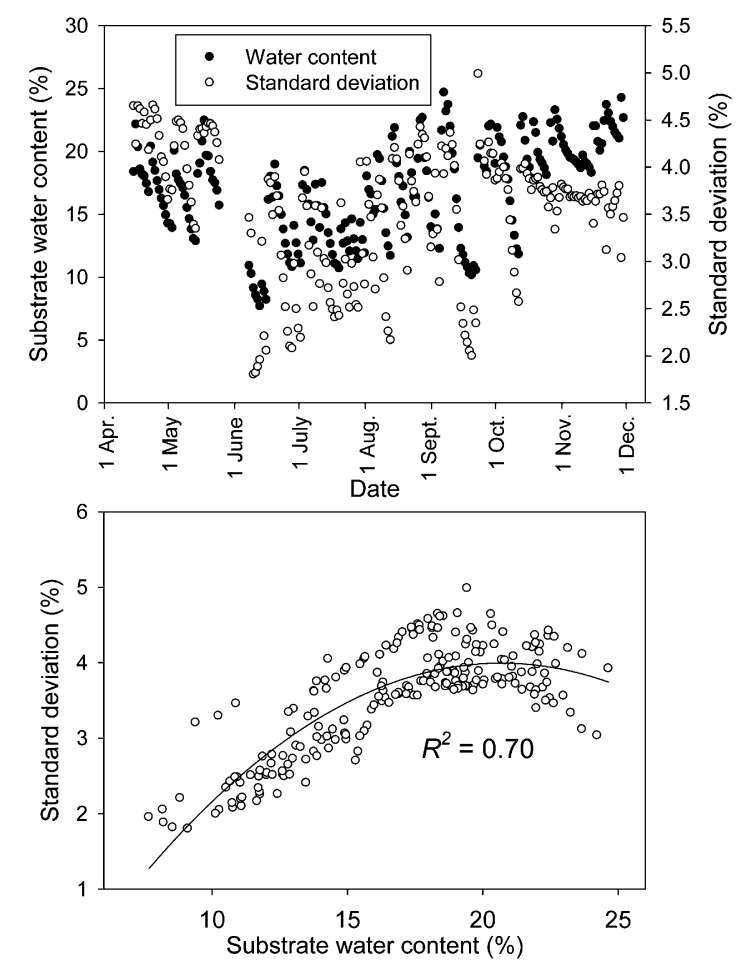

Fig. 2. Substrate volumetric water content and its standard deviation [top $(n=16)$ ] in green roof platforms over an 8-month period as measured at noon using capacitance soil moisture sensors (Echo-TM; Decagon Devices, Pullman, WA). Platforms were filled with a green roof substrate (M2; Stancills, Perryville, MD) and planted with stonecrop (Sedum kamtschaticum). Uniformity among sensor readings was greatest in very dry substrates and lowest in fairly wet substrates (bottom). Data courtesy of $O$. Starry. 
includes near-ultraviolet [ultraviolet $(\approx 280-400 \mathrm{~nm})$ ], visible $(400-700$ $\mathrm{nm})$, and near infra-red radiation $(700-3000 \mathrm{~nm})$. These wavelengths span most of the spectrum of radiation coming from the sun, although ultraviolet-C radiation $(100-280 \mathrm{~nm}$ ) is almost completely absorbed by the atmosphere and very little reaches the earth's surface. Shortwave radiation measurements, which use pyranometers, thus determine the total energy flux of the incoming sunlight [in units of watts per square meter (see Klassen and Bugbee, 2005 for a review of shortwave radiation measurements)].

Photosynthetically active radiation only includes light with wavelengths from 400 to $700 \mathrm{~nm}$ (Sager and Mc Farlane, 1997), roughly the same wavelengths visible to the human eye. Light within this part of the spectrum can be used by plants to drive photosynthesis and is measured in units of micromoles per square meter per second. Thus, measuring total shortwave radiation treats light as an electromagnetic wave and determines the energy in that radiation, while $P A R$ treats light as individual light particles (photons) and determines the number of photons in the incoming radiation.

Photosynthetically active radiation is measured using quantum sensors. Since these sensors measure the light spectrum that plants can use for photosynthesis, quantum sensors are often used when the collected data are needed for plant growth models. Such models can also be coupled to water use models, in which case quantum sensors can be used for irrigation management. Photosynthetically active radiation data are used in both very simple (e.g., van Iersel et al., 2010) and complex water use models (e.g., Bauerle and Bowden, 2011).

Photosynthetically active radiation data can also be used to calculate the daily light integral (DLI) by integrating PAR measurements over the course of the day (Korczynski et al., 2002). For accurate DLI calculations, it is important to measure $P A R$ frequently, especially on cloudy days, when $P A R$ can fluctuate rapidly, or in greenhouses, where the PAR sensor may at times be shaded by the greenhouse structure. In such cases, we recommend measuring $P A R$ once per minute, or more often. Frequent measurements are especially important if the data are used for modeling plant growth or water use. Weather stations typically do not include quantum sensors, but use pyranometers, net radiometers, or both, which measure the difference between incoming (or downward) and outgoing (upward) radiation in both the short- and long-wave parts of the spectrum (Campbell and Diak, 2005). Measuring shortwave radiation is critical in determining the energy balance of a leaf or crop. Energy balance calculations are used in the FAO Penman-Monteith model of ET and shortwave radiation measurements are thus critical for weather stations, if the weather data are to be used for ET modeling. Light intensities also are commonly measured with photometric sensors (although not as part of weather stations), in units of lux, lumens, or footcandles. Photometric sensors measure how well humans can detect the light. Since the sensitivity of the human eye is different from the way plants perceive light, these measures should not be used for irrigation control purposes. There is no direct conversion from photometric units to $P A R$ or shortwave radiation because that conversion depends on the spectral quality of the light. However, for sunlight, $1 \mu \mathrm{mol} \cdot \mathrm{m}^{-2} \cdot \mathrm{s}^{-1}=$ $\approx 5 \mathrm{fc}=\approx 5$ lumens $/ \mathrm{ft}^{2}=\approx 54 \mathrm{~lx}$.

The calibration of light sensors drifts gradually over time, and often in an unpredictable manner. To assure long-term reliability, sensors should be recalibrated every 2 to 3 years (see manufacturers' recommendations for more details). Recalibration requires a standard light source and generally needs to be done by the manufacturer. When many light sensors are used, a single sensor can be sent off for calibration, which can then be used as a secondary standard for calibration of the other light sensors, reducing calibration cost.

For accurate light measurements, it is essential that the sensor is clean, level, and, if possible, located so that it is not shaded or exposed to reflected radiation from nearby objects. Light sensors inside greenhouses will be shaded at times by the overhead structure of the greenhouse. This is acceptable, since the plants are exposed to similar shading.

Temperature, Relative HUMIDITY, AND VAPOR PRESSURE. Although they are different properties, temperature, $\mathrm{RH}$ and vapor pressure (e) are discussed together because their effects on plant water use are interdependent. Specifically, RH itself does not have a direct impact on (evapo)transpiration. Instead, the driving force for ET is the vapor pressure deficit [VPD (Jones, 1992)], which is a combined function of temperature and RH (Fig. 3). To better understand this relationship, a clear understanding of some key terms is needed. Vapor pressure is a measure of the actual amount of water vapor in the air, expressed in pressure units $(1 \mathrm{kPa}=$ 10 mbar). Saturation vapor pressure

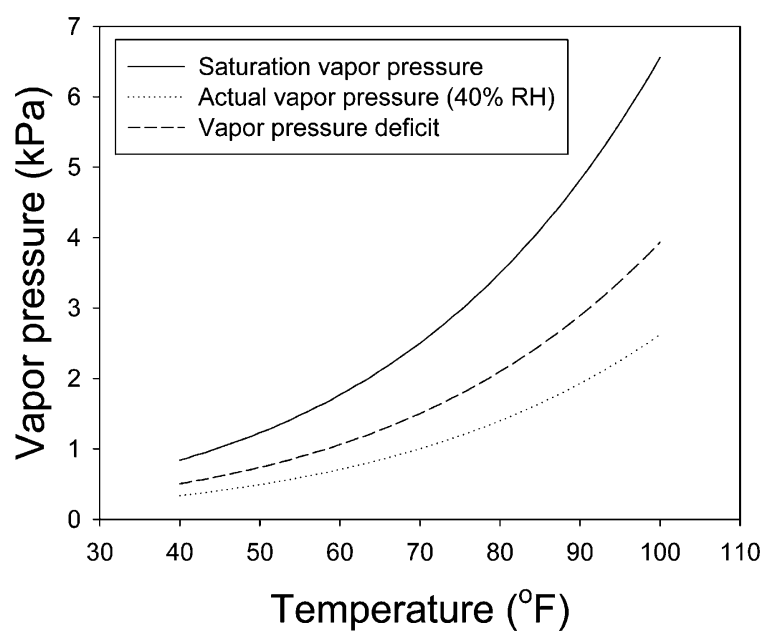

Fig. 3. The effect of temperature on saturation vapor pressure, actual vapor pressure, and vapor pressure deficit (saturation vapor pressure - actual vapor pressure $)$. Note that at constant relative humidity [ $\mathrm{RH}(40 \%$ in this example)], both the actual vapor pressure of the air and the vapor pressure deficit increase with increasing temperature because of the increase in the saturation vapor pressure with increasing temperature; $\left({ }^{\circ} \mathrm{F}-32\right) \div 1.8={ }^{\circ} \mathrm{C}, 1 \mathrm{kPa}=10 \mathrm{mbar}$. 
$\left(e_{\mathrm{s}}\right)$ is a measure of the maximum amount of water vapor the air can hold. This is a function of temperature, with warmer air being able to hold more water. Saturation vapor pressure is most commonly expressed in pressure units (kilopascals, millibars). Vapor pressure deficit is the difference between $e_{\mathrm{s}}$ and $e$ and is expressed in pressure units (kilopascals, millibars). Relative humidity is the ratio between the actual amount of water vapor in the air and the maximum amount of water vapor the air can hold at that temperature. It is most commonly expressed as a percentage $\left(e / e_{\mathrm{s}} \times 100\right)$ or sometimes as a fraction $\left(e / e_{\mathrm{s}}\right)$. Dew point temperature is the temperature to which the air must be cooled to completely saturate the air with water vapor (reach $100 \% \mathrm{RH})$. When the dew point is reached, dew (condensation) will form if the temperature drops further. Dry bulb temperature is the actual temperature of the air. Wet bulb temperature is the temperature of a thermometer covered with a wet wick and exposed to air flow. Evaporation of water from the wick will cool the thermometer. The wet bulb temperature is thus always lower than the air temperature, but higher than the dew point (unless $\mathrm{RH}=100 \%$, in which case wet bulb temperature, dry bulb temperature, and dew point are the same).

Since VPD is the driving force for $\mathrm{ET}$, it is a crucial variable in many plant water use models. Unfortunately, we cannot measure VPD directly. Weather stations normally determine VPD from the dry bulb temperature and RH. For applications that require great accuracy, dry bulb and dew point can be measured and used to calculate VPD, but accurate dew point measurements are too expensive and technically challenging for use in irrigation management. It is also possible, but uncommon, to determine VPD from dry and wet bulb temperature data.

Typically, weather stations include a temperature sensor and $\mathrm{RH}$ sensor. There are many different types of temperature sensors, but weather stations most commonly use either resistance temperature detectors (RTDs) or thermistors. Both sensor types are based on the same principle: the electrical resistance of the RTD or thermistor element changes with temperature and the resistance of the element is measured. This measured resistance is then used to determine the temperature, using a calibration equation. Although temperature measurements seem simple, large errors can occur if the sensor is not calibrated or used properly. Most importantly, temperature sensors should always be shaded and preferably aspirated. For guidelines for the construction of lowcost radiation shields, see Tarara and Hoheisel (2007)

Thermocouples also are commonly used for temperature measurements. They consist of two wires made of different metal, commonly copper and constantan, which make "type T" thermocouples. At one end, the two wires are in contact (welded together or simply touching) to create a junction. The Seebeck effect results in a voltage difference between the free ends of the two metal wires when the thermocouple junction and the free ends are at different temperatures. This voltage can be measured and is proportional to the temperature difference between the thermocouple junction and the free ends of the wires. Thus, thermocouples measure the temperature difference between the thermocouple junction and the free ends of the wires. To determine the actual temperature of the thermocouple junction, it is necessary to also measure the temperature close to the free ends of the two metal wires. This reference temperature is typically measured using an RTD or thermistor. The advantage of thermocouples is their low cost. Many thermocouples can be attached to a single wiring panel. As long as the temperature of the wiring panel is uniform and can be measured accurately, only one expensive temperature sensor is needed to collect temperature readings using multiple thermocouples.

Relative humidity is typically measured using capacitive sensors. These sensors contain a polymer or metal oxide substrate between two electrodes and the amount of water the substrate absorbs depends on the RH. The two electrodes are then used to measure the capacitance (for more details, see the section on capacitance soil moisture sensors) of the substrate and the resulting measurement is converted to a $\mathrm{RH}$ value. The calibration of $\mathrm{RH}$ sensors normally drifts gradually over time and these sensors should be recalibrated every 2 to 3 years to assure that the readings are accurate. See Baker (2005) for a review of RH measurements.

Automated weather stations or dataloggers can calculate $e_{\mathrm{s}}$ from the temperature, $e$ from $e_{\mathrm{s}}$ and the RH, and VPD from the $e_{\mathrm{s}}$ and $e$ (Fig. 3). Because $e_{\mathrm{s}}$ increases almost exponentially with increasing temperature, the VPD at a particular RH also increases with increasing temperature. For this reason, $\mathrm{RH}$ values are not particularly meaningful in the context of predicting plant water use and VPD should be used instead. To get the best possible accuracy, air temperature and $\mathrm{RH}$ should be measured in close proximity to each other, and the sensors are typically enclosed in the same radiation shield, often with both the temperature and $\mathrm{RH}$ sensor combined into a single instrument.

WIND. Wind affects ET because air movement moves the humid air away from the canopy or soil/substrate and reduces the boundary layer resistance for water movement from the soil/substrate or crop to the air (Jones, 1992). Wind direction is generally less critical for irrigation management but is measured by most weather stations as well. The most common method to measure wind speed is with cup anemometers. Wind causes the cups to rotate around a vertical shaft and the number of rotations within a particular time interval is measured to determine the wind speed.

Another type of anemometer is the windmill type, where a propeller is spun by the wind and the rotations of the propeller are measured. To assure that the propeller is perpendicular to the wind, a wind vane is normally used to align the instrument to the prevailing wind direction. Hot wire anemometers are frequently used in research applications and consist of wire with an electrical current going through it. This current changes the temperature and thus the electrical resistance of the wire. Wind will cool the wire and the actual temperature and resistance of the wire are thus dependent on the wind speed. The resistance of the wire can be measured using several different approaches, but the basic operating principle of all hot wire anemometers is the same. Sonic anemometers use ultrasonic signals to measure wind speed and direction. The measurement principle is that air movement affects the time it 
takes for an ultrasonic pulse to travel from one transducer to another. Based on the number and orientation of the transducers, sonic anemometers can measure wind speed, direction, or both in two (speed and direction) or three dimensions. Three-dimensional measurements are particularly useful for eddy covariance systems, such as enclosed greenhouses, where turbulent air movement needs to be measured (Campbell Scientific, 2012). Although generally not critical for irrigation applications, wind direction is normally measured by weather stations using a vane. This vane can rotate and its angle depends on the prevailing wind direction. At very low wind speed, the wind may not have enough force to push the vane around, and wind direction measurements can become inaccurate. See Hubbard and Hollinger (2005) for a history and review of wind speed and direction measurements.

RaINFALl. Rainfall is obviously critical in irrigation applications and is generally measured using a tipping bucket rain gauge. Rainfall is collected into a funnel and the water is directed toward a spoon-like device. When enough water collects in this spoon, it will tip, causing an electrical pulse signal to be sent (using a reed switch). Weather station rain gauges typically have a resolution of $0.2 \mathrm{~mm}$. The precision of rain gauges depends on whether they are single or doubletip gauges. Especially during intense rainfall events, single-tip rain gauges may be less accurate than double-tip rain gauges. The volume of the tipping device is also important, especially in high rainfall areas like the tropics, or where they are used for measuring runoff from experimental areas (Starry, 2013). Rainfall can also be measured using simple rain gauges, which accumulate rainwater in a graduated collection reservoir. Such rain gauges do not allow for automated data collection and are therefore not used as part of weather stations.

Ideally rain gauges would not just determine the daily amount of rainfall but also the intensity of the rainfall (i.e., the rate at which it rains). Rainfall intensity, in many situations, will help determine how much water will infiltrate the soil/substrate and how much water may be lost as surface runoff or by leaching (Cuomo and Della Sala, 2013). Although most automated weather stations are capable of measuring rainfall intensity, they are often not configured to do so. This is an area where it would be easy to make progress toward making weather data more usable.

Some landscape irrigation controllers do not base irrigation on the amount of rain that has fallen, but simply shut off or prevent irrigation in the case of rainfall. The use of rainfall sensors to override an irrigation system will likely not result in optimal irrigation since a rainfall sensor cannot determine whether a particular crop has received enough rain to bring the soil/substrate moisture level back into the optimal range.

\section{Soil versus plant sensing}

Weather data are particularly important for modeling crop water requirements. Alternatively, irrigation decisions can be based on direct measurements of plant or soil/substrate water status. There are varying opinions about whether plant or soil/ substrate measurements are better suited for automated irrigation decision-making. Proponents of measuring crop water status argue that the goal of irrigation is to assure adequate water availability to the crop and that crop water status is therefore the best indicator of whether irrigation is needed. However, crop water status is generally more difficult and expensive to measure than soil water status. In addition, crop water status is not only affected by the availability of water in the soil, but also by short-term changes in weather (such as clouds passing over) and by diseases and pests (particularly those that affect the root system and thus the water uptake of the crop). Thus, changes in plant water status are not necessarily indicative of changes in water availability in the root zone of the plant. Soil water measurements have the advantage that they are relatively easy to make and to automate. In addition, using soil/substrate water status to make irrigation decisions results in a simple feedback system: a low soil/substrate VWC will trigger irrigation, which increases soil/substrate VWC and indicates that irrigation is no longer needed. We have decided to focus our research efforts on measurements of soil/substrate VWC for automated irrigation control, and measurements of crop water status are therefore not covered in this overview. For a review of plant-based approaches, see Jones (2004).

Both crop and soil measurements need to take into account spatial and temporal variability. Soils are often not homogenous, resulting in spatial differences in soil VWC of both field and container-grown plants. Plants contribute to both spatial and temporal variability in soil water measurements. The distribution and density of roots in the soil profile adds to spatial differences because of preferential water uptake from specific areas in the root zone. Understanding and quantifying this spatial variability will greatly improve the quality of information gained from soil/substrate environments. Water uptake by plants also increases temporal variability of the water in the soil/substrate. For example, plants grown in containers can quickly deplete the available water in the substrate, adding a temporal dimension to the sensor data that may not be seen in field-grown horticultural crops. In situations where the available water is used quickly, more frequent measurements may be needed to assure adequate temporal resolution. In specific cases, it may be advantageous to place soil sensors to quantify both spatial and temporal dynamics, for example, using water and EC sensors to follow water and nutrient movement through the soil/substrate profile.

Crops, likewise, are not homogenous. Spatial variability within the crop can result from natural variability among the plants, spatial variability of the soil, uneven fertilizer application, or environmental gradients within the production area. This heterogeneity within a crop can result in spatial differences in crop water use and soil moisture. In addition, there are distinct diurnal patterns in crop water status that can make plant water status data difficult to interpret. Remote sensing applications can alleviate issues related to spatial variability to some extent, either by measuring many plants and reporting an average or by mapping the spatial variability. For an excellent review on the implications of spatial and temporal variation on irrigation management, see the reviews by Jones (2004, 2007).

In many cases, the largest reason for spatial variability may actually be the design of the irrigation system itself: distribution uniformity in many 
cases is poor (Fare et al., 1992). If the uniformity of the irrigation system is not good, spatial variability in soil/ substrate VWC and plant growth will be the inevitable result. Thus, any efforts to implement precision irrigation need to start with proper design, installation, and maintenance of the irrigation system (see Ross, 2008).

\section{Sensing soil/substrate water status}

Water content vs. matric potential

Two basic properties of soil/substrate can be measured, soil VWC and soil matric (or water) potential. There is no agreement which measure is better suited for irrigation management (see Jones, 2007). Soil water content sensors, as the name implies, measure the amount of water in the soil, while matric potential sensors measure how easy it is for plants to extract water from the soil/substrate (i.e., how tightly the water is bound to the soil/substrate matrix). Matric potential and soil/substrate VWC are related to each other, but this relationship is different for different soils and substrates and depends on the pore size distribution of the soil/substrate; larger pores hold water less strongly than small pores. The relationship between VWC and matric potential can be determined from moisture release curves (Fig. 4).

Soil/substrate VWC measurements therefore indicate how much water is present, but not whether this water is actually available to the crop. This is critical in understanding the limitations of soil water content sensors: a VWC of $20 \%\left(0.20 \mathrm{~m}^{3} \cdot \mathrm{m}^{-3}\right)$, for example, provides no usable information about whether that water is available to the plant and whether irrigation is needed. For example, in soils with high clay content, a $20 \%$ VWC likely means that there is little or no plant-available water in the soil: the water is bound tightly to the soil matrix and plants cannot easily access that water; in this case, irrigation is needed. In a sandy soil, on the other hand, $20 \%$ may be near field capacity and much of this soil water is readily available to the plant. Irrigation likely would simply result in draining of water through the profile below the root zone or runoff. Similar differences exist among soilless substrates. To be able to interpret VWC measurements, a basic understanding of
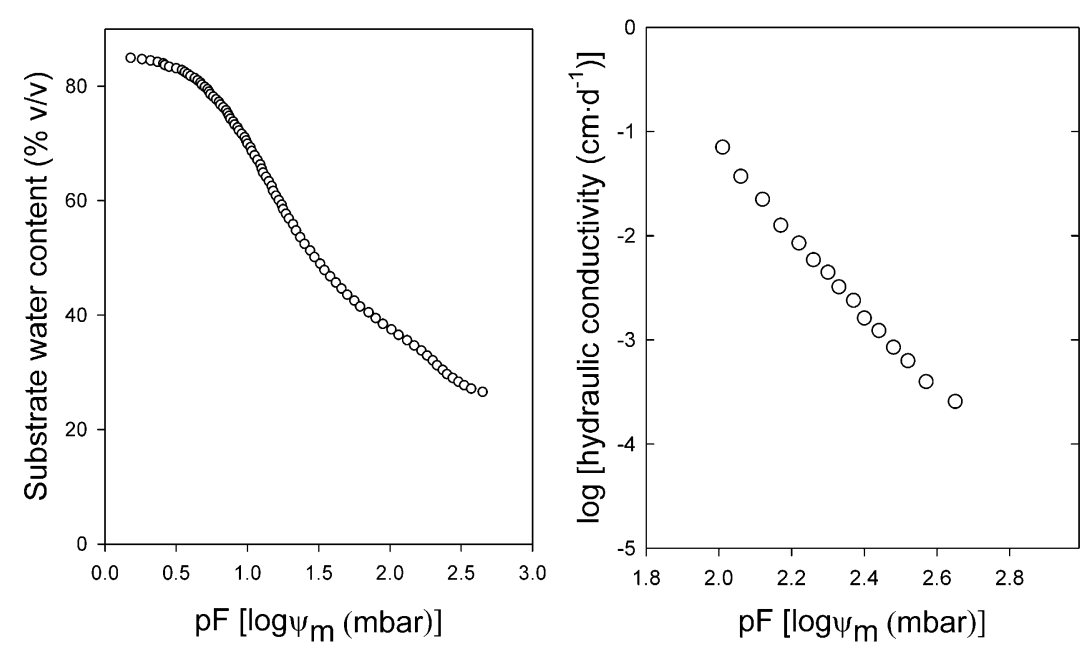

Fig. 4. A substrate moisture retention curve ( $\mathrm{pF}$ vs. volumetric water content) and the hydraulic conductivity as a function of $\mathrm{pF}$ for a soilless substrate containing $80 \%$ peat and $20 \%$ perlite. $\mathrm{pF}$ is the $\log _{10}$ of the matric potential $\left(\psi_{\mathrm{m}}\right)$ expressed in millibars. Note that the hydraulic conductivity curve only covers a pF range of $\approx 2$ to $2.65 \mathrm{mbar}$ (or about $36 \%$ to $28 \%$ water content). Within this limited range of water content, hydraulic conductivity drops by a factor of 300 . Data were collected using a Hyprop (UMS, München, Germany) (M.W. van Iersel, unpublished results); 1 mbar $=0.1 \mathrm{kPa}, 1 \mathrm{~cm}=0.3937$ inch .

soil/substrate properties is essential. When this information is available, soil VWC measurements make it easy to use those data for irrigation management because it is simple to calculate how much water needs to be applied when the irrigation is turned on. Alternatively, lysimeters can be used to measure changes in soil water content. Weighing containers with plants provides direct information on how much water is lost through ET. Although lysimeter measurements do not provide information on the actual soil water content, water loss information can be used to make irrigation decisions (e.g., Beeson, 2011; Prehn et al., 2010).

Soil matric potential has the advantage that it directly determines whether the soil water is available to the plants. Once an appropriate threshold for a particular plant/crop has been determined (e.g., Lemay et al., 2012), this threshold can be used in different situations, regardless of soil/substrate type. However, matric potential data provide no information on how much water should be applied. To determine this, an understanding of the properties of that soil is required.

Note that traditionally, substrate matric potential has been used to indicate whether water in soilless substrates is available to plants, with a matric potential of -20 to $-30 \mathrm{kPa}$ often considered the lower limit for plant-available water. However, this ignores the role of the hydraulic conductivity of the substrate, which indicates the ability of water to move through the substrate along matric potential gradients. The hydraulic conductivity of soilless substrates decreases dramatically with decreasing substrate VWC (Fig. 4), and the importance of hydraulic conductivity in soilless substrates is still poorly understood.

\section{Water content sensing}

Most soil water content sensors take advantage of the high dielectric of water. The dielectric refers to the interaction of water molecules with an electromagnetic field. Most soil/ substrate materials have a very low dielectric (about 4), air has a dielectric of 1 , and water has a dielectric of about 80 . Thus, changes in soil/substrate VWC have a significant effect on the total dielectric of the soil. Sensors can measure the dielectric of the soil/substrate and convert those values to soil/substrate water content. Among sensor types that use the dielectric properties of soils are time-domain reflectivity (TDR) sensors, time-domain transmissometry (TDT), and capacitance sensors. TDR has long been the standard method of measuring the dielectric properties of soil; TDR sensors are inexpensive, 
but an expensive meter is needed to measure their output. In the last decade, other approaches have been developed to use the dielectric properties of soils (TDT, capacitance). These newer sensors do not require an expensive meter and have facilitated the incorporation of soil moisture sensors into irrigation control systems, including the wireless sensor networks developed for the Specialty Crop Research Initiative-Managing Irrigation and Nutrition through Distributed Sensing (SCRI-MINDS) project. As part of this project we have learned that the quality of sensor readings can be greatly improved in several ways.

Calibration. Despite claims from some manufacturers, all sensors that rely on the dielectric properties of soils/substrate benefit from a soil/ substrate specific calibration. There are large enough differences among the dielectric properties of different types of soils/substrates and the interaction of soils/substrates with water to affect the measured dielectric. This becomes especially critical if such sensors are used in soils with high organic matter content, high salinity, or in soilless, highly porous substrates used in horticulture (e.g., Crespo and van Iersel, 2011; Fig. 5). Simple calibration procedures are discussed by Belayneh et al. (2013) and Nemali et al. (2007).

SENSOr positioning. It is important in any environment, particularly when measurements are being made at the microscale (e.g., in container production). Roots and irrigation water are typically not distributed uniformly in the substrate, and sensor choice and placement thus contribute significantly to precision and repeatability of data. For sensor data to be representative of plant water uptake, sensors need to be placed in that part of the root zone where active water uptake occurs.

Sensors also need to be inserted into the soil/substrate carefully. Since the dielectric of air is very low, air spaces around the sensor will reduce the measured dielectric and water content. Thus, care should be taken to minimize creating airspaces during insertion of the sensor. Air spaces can be formed as the result of sideways movement of the sensor or if the sensor catches a piece of substrate and drags it along during insertion. Using sharp knife to cut a slot for the sensor can

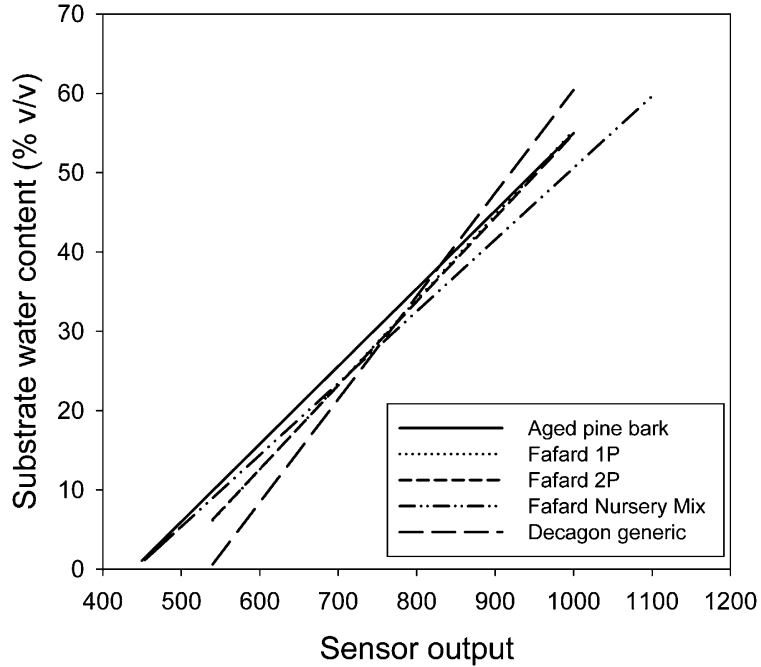

Fig. 5. Calibration of soil moisture sensors (EC-5; Decagon Devices, Pullman, WA) in different soilless substrates, with the sensors connected to a data logger (EM50, Decagon Devices), as compared with the generic calibration for soilless substrates as provided by Decagon Devices. Note that The Fafard $1 P$ and $2 P$ substrates (Sungro, Agawam, MA) contain mainly sphagnum peat and perlite and have a near-identical calibration, while the Fafard Nursery Mix contains mainly pine bark and has a calibration similar to the aged pine bark.

ease sensor insertion. Measurement inaccuracies due to air spaces typically improve over time as soil/substrate particles settle around the sensor. This can be sped up by saturating the soil/substrate around the sensor after insertion. This type of variation in sensor readings is especially important when sensors are used for "spotchecking" different zones in production. Typically, spot measurement can deviate by as much as $25 \%$ from real values in porous soilless substrates (J.D. Lea-Cox, personal observation).

FREQUENCY OF MEASUREMENTS. The optimal frequency of data collection depends on how quickly soil/ substrate water content changes. The most rapid changes occur during irrigation or rainfall, and shortly thereafter, especially if leaching occurs. If substrate water content in the bottom of the root zone drops very rapidly following irrigation (more rapidly than can be attributed to plant water use), this indicates leaching (e.g., Chappell et al., 2013). If data are collected frequently enough to detect this (typically every $15 \mathrm{~min}$ ), this information can be used to reduce irrigation durations and consequently minimize leaching.

Soil water content data can also be used to get quantitative information about plant water use by looking at the rate of decrease in soil/substrate water content (Fig. 6). The more water the plants use, the more rapidly the soil/substrate water content will decrease (van Iersel et al., 2011). For a more in-depth review of different methods to measure soil/substrate water content, including several techniques not discussed here (neutron probes, soil thermal properties, and soil resistivity), please see Bittelli (2011).

\section{Lysimeters/load cells}

Lysimeters can be used to continuously measure the weight of a certain volume of soil or a container with substrate, along with the plant(s) growing in it. The decrease in weight over time is an indication of the amount of water lost through transpiration, evaporation, or leaching (if applicable). This decrease in weight can then be used to determine how much water needs to be applied to replenish the soil/substrate, thus providing a simple and direct method for irrigation control (Beeson, 2011; Prehn et al., 2010). Lysimeters can also be used to quantify the daily water loss from containers (O'Meara et al., 2013).

Although the increase in the weight of the plant is negligible in the short term, over time, increasing plant weight needs to be taken into account. Otherwise, if irrigation is set to maintain a constant weight (of plant plus soil/substrate), the increasing 
plant weight will result in a decrease in soil/substrate water content (Fig. 7; Kim and van Iersel, 2011). This potential problem can be negated by irrigation to saturation at regular intervals and using the weight measured after drainage as the new reference weight (Prehn et al., 2010).

The simplest lysimeters consist of a load cell mounted on a base and with a weighing platform (O'Meara et al., 2013; Prehn et al., 2010) or a platform hanging from a load cell (Beeson, 2011). When using load cells, temperature sensitivity of the load cells needs to be taken into account. This temperature sensitivity can be significant, differs among load cells of the same type, and often exceeds the specifications of the manufacturer (M. van Iersel, unpublished results). For temperature correction, the temperature sensitivity of each individual load cell needs to be characterized over the entire range of expected temperatures. To get adequate resolution, it is important to match the measurement range of the load cell to the weight of the plants being measured.

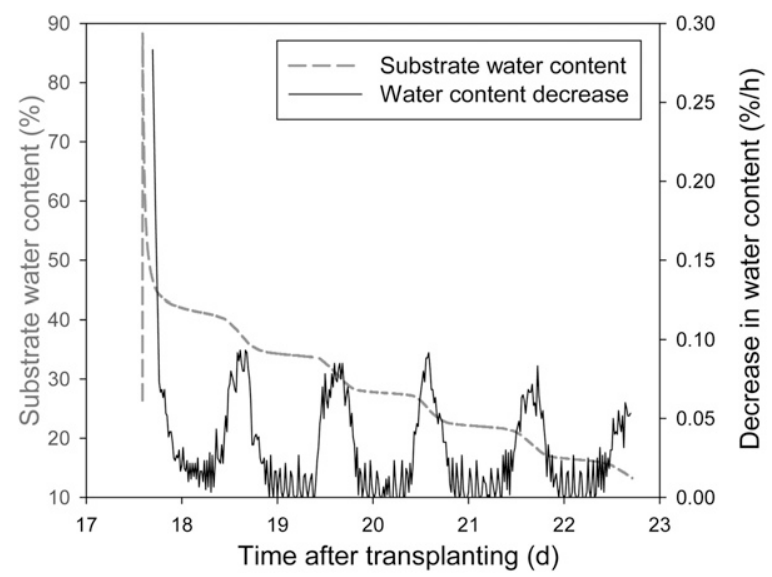

Fig. 6. Substrate volumetric water content (left $y$-axis) and the rate of decrease of the substrate water content over the course of $5 \mathrm{~d}$. Plants were irrigated only on day 17. Note the very high rate of decrease in substrate water content immediately after irrigation on day 17. This decrease in substrate water content is indicative of leaching.

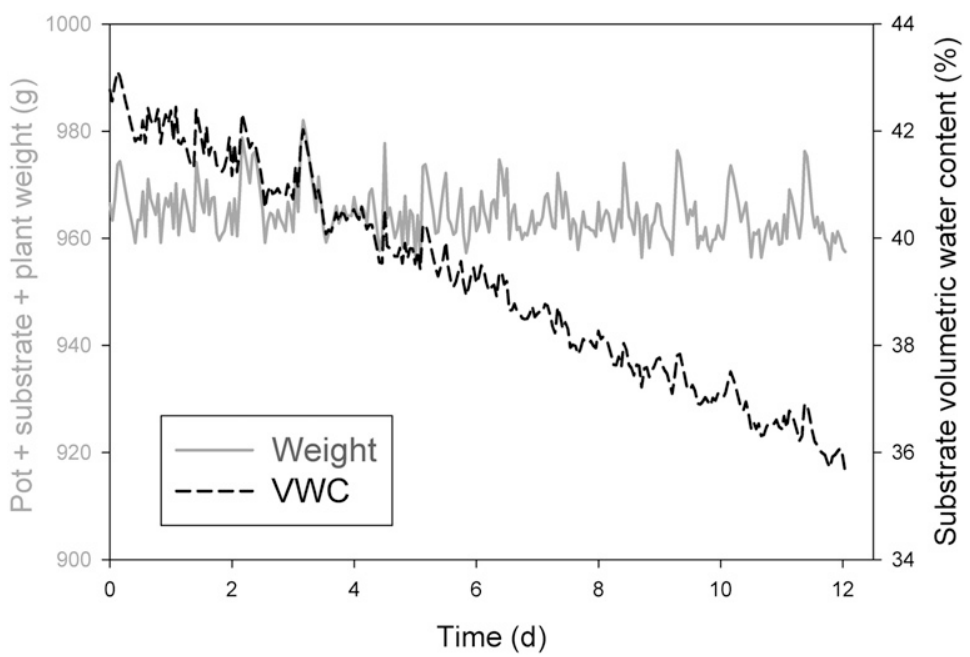

Fig. 7. Irrigation of a container with vinca (Catharanthus roseus) plants with the goal of maintaining a steady weight of the container, substrate, and plants. Although the weight was maintained within a narrow range, the volumetric water content (VWC) of the substrate declined gradually. This decrease is due to the increasing weight of the plants (figure adapted from Kim and van Iersel, 2011); $1 \mathrm{~g}=0.0353 \mathrm{oz}$.

\section{Matric potential sensing}

Matric potential of the soil is most commonly measured using tensiometers. Tensiometers measure soil matric potential (suction) directly, and the results do not depend on soil type or texture. No soil/substrate specific calibration is needed. Most tensiometers require routine maintenance because they contain water, which needs to be replenished on a regular basis. In addition, maintaining good contact between the ceramic tensiometers tip and the surrounding soil/substrate is needed to prevent air from entering the ceramic tip (LeaCox, 2012). If the suction in the tensiometers becomes too great, cavitation can occur, rendering the data meaningless. Both air entering the tensiometers and cavitation are typically clearly visible in the data since they result in a sudden and rapid increase in matric potential. If such an increase occurs, and is not associated with rain or irrigation, it indicates a malfunction of the tensiometers.

Certain tensiometers are specially designed for use in soilless substrates and have special ceramic tips that allow for faster equilibration with the surrounding substrate. Such tensiometers are typically more accurate and can measure matric potentials close to $0 \mathrm{kPa}$. This can be important because of the rapid changes in substrate matric potential that can occur in containers.

More recently, hybrid sensors have been developed that apply the principle of dielectric sensors to determine matric potential. A dielectric sensor is embedded in a ceramic material (matrix) and the matric potential of this ceramic material equilibrates with the matric potential of the surrounding soil/substrate. The dielectric sensor is then used to measure the dielectric of the ceramic material and this value is then converted to a soil matric potential. Like soil water content sensors, tensiometers have been used successfully to automate irrigation of ornamental plants grown in soilless substrates (e.g., Hansen and Pasian, 1999; Kiehl et al., 1992).

\section{Soil/substrate salinity}

Salinity measurements are important in irrigation management because irrigation water not only applies water to a crop, but may also apply salts, water-soluble fertilizer, or both. 
The measurement of salinity can be used in the prevention of salt build up in the soil/substrate. Excessive salinity can affect soil structure, induce osmotic stress, cause ion-specific toxicity, and alter uptake of essential nutrients (Havlin, 2005). Salinity levels in soils/substrates are generally determined by their ability to conduct electricity [electrical conductivity (EC)]. Such measurements can either determine the EC of the combined soil/ substrate particles, air, and solution (bulk EC) or the EC of the water in the soil/substrate (pore water EC); EC is expressed in decisiemens per meter, millisiemens per centimeter, or millimhos per centimeter (these units are equivalent).

Although the most accurate methods of determining soil salinity are laboratory-based tests (which determine pore water EC, typically after dilution), there has been significant progress with in situ EC measurements. Soil/substrate EC can be determined from the dielectric properties of the soil/substrate, which makes it possible for techniques like TDR to measure both soil water content and EC simultaneously (Dalton and van Genuchten, 1986). Alternatively, soil/ substrate EC can be measured using electrodes by measuring the conductance (the inverse of resistance) of the soil/substrate.

One difficulty with both in situ methods is that they measure a property referred to as the bulk soil EC, or the ability of the combination of soil/ substrate particles, air spaces, and the solution to conduct electricity. This property has little practical value because it is greatly dependent on soil water content (Scoggins and van Iersel, 2006) and thus is a poor indicator of the amount of nutrients present in the soil. Hilhorst (2000) developed a model for converting bulk soil EC to solution (pore water) EC using the dielectric of the soil/substrate. This pore water algorithm has been incorporated in new EC sensors that are now commercially available [e.g., WET-2 sensor (Delta-T Devices, Burwell, UK), GS-3 sensor (Decagon Devices, Pullman, WA)].

\section{Sensing the irrigation system}

Sensors are not only useful to determine when and how much to irrigate but also play an important role in checking the performance of the irrigation system, and can be used to detect maintenance problems. The most useful parameters to measure are flow rate, water pressure, solution EC, and $\mathrm{pH}$.

Flow METERs. Flow meters should be part of any commercial irrigation system. Not only do they provide a record of water use, they also can be used for troubleshooting purposes, such as leak detection. There are many flow meters available that can easily be incorporated into larger sensor networks (Belayneh et al., 2013). The most common flow meters have a paddle wheel that rotates faster as the flow rate increases. If such meters are equipped with a reed (pulse) switch, they can easily be integrated into sensor networks.

WATER PRESSURE. Measuring the water pressure in the irrigation system is valuable for leak detection (since leaks can reduce water pressure) and also to assure that there is adequate pressure for proper operation of the irrigation system, particularly the optimal operating pressure of sprinklers/emitters. A lack of pressure is especially common in large irrigation systems that use multiple valves. If too many irrigation valves open at once, water pressure may be too low for the irrigation system to function properly.

Electrical conductivity. The EC is an indicator of the amount of dissolved salts in solution, as described above. In the case of irrigation, these salts can come either from the irrigation water itself (alkalinity or salinity) or from water-soluble fertilizer injected into the irrigation water. Therefore EC sensors can be used to determine whether fertilizer injectors are working properly and to quantify the concentration of fertilizer in solution. This can be done using the EC of the irrigation water before fertilizer is injected $\left(\mathrm{EC}_{\mathrm{w}}\right)$, the $\mathrm{EC}$ of the fertilizer solution after fertilizer has been injected $\left(\mathrm{EC}_{\mathrm{f}}\right)$, and the increase in solution EC resulting from every 100 ppm nitrogen $\left(\mathrm{EC}_{100 \mathrm{PPM}} \mathrm{N}\right.$, which can normally be found on the fertilizer label). Based on this information, the $\mathrm{N}$ concentration of the fertilizer solution (in parts per million $\mathrm{N}$ ) can be calculated as $100 \times\left(\mathrm{EC}_{\mathrm{f}}-\mathrm{EC}_{\mathrm{w}}\right) /$ $\mathrm{EC}_{100 \mathrm{pPm} \mathrm{N}}$. Likewise, EC meters can be used to measure fertilizer concentrations in fertilizer tanks, as well as in the leachate or drainage solution. Measurements can be made using handheld meters or sensors that are integrated into automated measurement and control systems. Electrical conductivity sensors typically have two or four electrodes. Sensors with four electrodes are much less sensitive to contamination (Decagon Devices, 2012) and have a wider measurement range than sensors with two electrodes. Calibration of EC sensors is typically fairly stable, if the electrodes are clean and is easily checked with standard solutions. Electrical conductivity measurements are temperature sensitive and most EC meters have a temperature sensor built in for automated temperature correction to either 20 or $25^{\circ} \mathrm{C}$. The temperature adjustment is typically done assuming a temperature sensitivity of $2 \%$ per degree Celsius. However, the exact temperature sensitivity depends on the type and concentration of salts present, the actual temperature of the solution, and the temperature to which the data are adjusted (Smith, 1962).

$\mathrm{pH}$. Irrigation water or fertilizer solution $\mathrm{pH}$ measurements are especially important in hydroponic systems or in cases where acid is injected into the irrigation water to counter alkalinity. Solution $\mathrm{pH}$ affects nutrient availability since $\mathrm{pH}$ values that are too low or too high may cause precipitation of fertilizer salts and lower the efficacy of chelating agents (Havlin, 2005). Solution $\mathrm{pH}$ is especially critical in determining micronutrient availability (both deficiency and toxicity), with elements such as iron and manganese. When the irrigation water is alkaline, acid can be injected to lower the $\mathrm{pH}$ (Bailey and Bilderback, 1997). $\mathrm{pH}$ measurements of the irrigation water with injected acid can be used to assure proper dosage of the acid. Most $\mathrm{pH}$ sensors have a glass electrode, need regular refilling, and frequent calibration. Calibration is commonly done using two standard solutions, with $\mathrm{pH}$ of 4.0 and 7.0. Less common are ion-sensitive fieldeffect transistor $\mathrm{pH}$ sensors, which do not need refilling, but still require regular calibration.

\section{Conclusions}

Sensing environmental and soil/ substrate conditions can provide information that can be used to greatly increase the efficiency of irrigation systems and to control performance. It is important to realize that sensors 
can be used to collect large amounts of data, but these data have little value without efficient ways to collect, store, and process them. First of all, for large scale sensing, appropriate hardware is needed. An example of the development of the hardware and software needed for wireless sensor networks is described by Kohanbash et al. (2013). Our group has successfully deployed this newly developed hardware and software for on-farm irrigation scheduling (Belayneh et al., 2013; Chappell et al., 2013). Irrigation can be based on soil/substrate VWC measurement or on models that predict crop water use (e.g., Bauerle et al., 2002; Kim et al., 2011). A survey of the greenhouse and nursery industry has shown that there is widespread interest in the use of sensor networks for irrigation monitoring and control (Majsztrik et al., 2013), and this may help move the industry from irrigation practices that rely heavily on qualitative indicators of crop water needs to more quantitative methods. We have already seen that such a switch to more quantitative irrigation methods can help save large amounts of water (Belayneh et al., 2013; Chappell et al., 2013) and increase growers profits (Lichtenberg et al., 2013).

\section{Literature cited}

Allen, R.G., L.S. Pereira, D. Raes, and M. Smith. 1998. Crop evapotranspiration (guidelines for computing crop water requirements). FAO Irr. Drainage Paper No. 56.

Bailey, D.A. and T. Bilderback. 1997. Alkalinity control for irrigation water used in nurseries and greenhouses. North Carolina State Univ. Hort. Info. Lflt. 558.

Baille, M., A. Baille, and J.C. Laury. 1994. A simplified model for predicting evapotranspiration rate of nine ornamental species vs. climate factors and leaf area. Sci. Hort. 59:217-232.

Baker, J.M. 2005. Humidity, p. 31-42. In: J.L. Hatfield and J.M. Baker (eds.). Micrometeorology in agricultural systems. Amer. Soc. Agron., Madison, WI.

Bauerle, T.L., W.L. Bauerle, M. Goebel, and D.M. Barnard. 2013. Root system distribution influences substrate moisture measurements in containerized ornamental tree species. HortTechnology 23:754-759.

Bauerle, W.L. and J.D. Bowden. 2011. Separating foliar physiology from mor- phology reveals the relative roles of vertically structured transpiration factors within red maple crowns and limitations of larger scale models. J. Expt. Bot. 62: 4295-4307.

Bauerle, W.L., C.J. Post, M.F. McLeod, J.B. Dudley, and J.E. Toler. 2002. Measurement and modeling of the transpiration of a temperate red maple container nursery. Agr. For. Meteorol. 114:45-57.

Bayer, A., I. Mahbub, M. Chappell, J. Ruter, and M.W. van Iersel. 2013. Water use and growth of Hibiscus acetosella 'Panama Red' grown with a soil moisture sensor controlled irrigation system. HortScience 48:980-987.

Beeson, R.C. 2010. Modeling actual evapotranspiration of Viburnum odoratissimum during production from rooted cuttings to market size plants in 11.4-L containers. HortScience 45:1260-1264.

Beeson, R.C. 2011. Weighing lysimeter systems for quantifying water use and studies of controlled water stress for crops grown in low bulk density substrates. Agr. Water Mgt. 98:967-976.

Beeson, R.C. 2012. Development of a simple reference evapotranspiration model for irrigation of woody ornamentals. HortScience 47:264-268.

Belayneh, B.E., J.D. Lea-Cox, and E. Lichtenberg. 2013. Costs and benefits of implementing sensor-controlled irrigation in a commercial pot-in-pot container nursery. HortTechnology 23:760-769.

Bittelli, M. 2011. Measuring soil water content: A review. HortTechnology 21: 293-300.

Campbell, G.S. and G.R. Diak. 2005. Net and thermal radiation estimation and measurement, p. 59-104. In: J.L. Hatfield and J.M. Baker (eds.). Micrometeorology in agricultural systems. Amer. Soc. Agron., Madison, WI.

Campbell Scientific. 2012. CSAT3 three dimensional sonic anemometer. Instruction manual. Campbell Scientific, Logan, UT.

Chappell, M., S.K. Dove, M.W. van Iersel, P.A. Thomas, and J. Ruter. 2013. Implementation of wireless sensor networks for irrigation control in three container nurseries. HortTechnology 23:747-753.

Crespo, J.M. and M.W. van Iersel. 2011. Performance of a soil moisture sensorbased landscape irrigation controller for automated irrigation of container-grown plants. HortScience 46:889-894.

Cuomo, S. and M. Della Sala. 2013. Rainfall-induced infiltration, runoff and failure in steep unsaturated shallow soil deposits. Eng. Geol. 162:118-127.
Dalton, F.N. and M.T. van Genuchten. 1986. The time-domain reflectometry method for measuring soil water content and salinity. Geoderma 38:237-250.

Daniels, A.B., D.M. Barnard, P.L. Chapman, and W.L. Bauerle. 2012. Optimizing substrate moisture measurements in containerized nurseries. HortScience 47: 98-104.

Decagon Devices. 2012. ES-2, ES-2F. Electrical conductivity \& temperature sensor. Operator's manual. Version 1. Decagon Devices, Pullman, WA.

Fare, D.C., C.H. Gilliam, and G.J. Keever. 1992. Monitoring irrigation at container nurseries. HortTechnology 2:75-78.

Hand, D.J. 2010. Measurement theory and practice: The world through quantification. Wiley, Hoboken, NJ.

Hansen, R.C. and C.C. Pasian. 1999. Using tensiometers for precision microirrigation of container grown roses. Appl. Eng. Agr. 15:483-490.

Havlin, J.L. 2005. Soil fertility and fertilizers. An introduction to nutrient management. 7th ed. Prentice Hall, Englewood Cliffs, NJ.

Hilhorst, M.A. 2000. A pore water conductivity sensor. Soil Sci. Soc. Amer. J. 64:1922-1925.

Hubbard, K.G. and S.E. Hollinger. 2005. Standard meteorological measurements, p. 1-30. In: J.L. Hatfield and J.M. Baker (eds.). Micrometeorology in agricultural systems. Amer. Soc. Agron., Madison, WI.

Jones, H.G. 1992. Plants and microclimate. A quantitative approach to environmental plant physiology. Cambridge Univ. Press, Cambridge, UK.

Jones, H.G. 2004. Irrigation scheduling: Advantages and pitfalls of plant-based methods. J. Expt. Bot. 55:2427-2436.

Jones, H.G. 2007. Monitoring plant and soil water status: Established and novel methods revisited and their relevance to studies of drought tolerance. J. Expt. Bot. 58:119-130.

Kiehl, P.A., J.H. Lieth, and D.W. Burger. 1992. Growth response of chrysanthemum to various container medium moisture tension levels. J. Amer. Soc. Hort. Sci. 117:224-229.

Kim, J. and M.W. van Iersel. 2011. Slowly-developing drought stress increases photosynthetic acclimation of Catharanthus roseus. Physiol. Plant. 143:166-177.

Kim, J., M.W. van Iersel, and S.E. Burnett. 2011. Estimating daily water use of two petunia cultivars based on plant and 
environmental factors. HortScience 46:1287-1293.

Klassen, S. and B. Bugbee. 2005. Shortwave radiation, p. 43-58. In: J.L. Hatfield and J.M. Baker (eds.). Micrometeorology in agricultural systems. Amer. Soc. Agron. Madison, WI.

Klassen, S.P., G. Ritchie, J.M. Frantz, D. Pinnock, and B. Bugbee. 2003. Real-time imaging of ground cover: Relationships with radiation capture, canopy photosynthesis, and daily growth rate, p. 3-15. In: T. Vantoai (ed.). Digital imaging and spectral techniques: Applications to precision agriculture and crop physiology. Amer. Soc. Agron., Madison, WI.

Kohanbash, D., G. Kantor, T. Martin, and L. Crawford. 2013. Wireless sensor network design for monitoring and irrigation control: User-centric hardware and software development. HortTechnology 23:725-734.

Korczynski, P.C., J. Logan, and J.E. Faust. 2002. Mapping monthly distribution of daily light integrals across the contiguous United States. HortTechnology 12:12-16.

Lampinen, B.D., V. Udompetaikul, G.T. Browne, S.G. Metcalf, W.L. Stewart, L. Contador, C. Negrón, and S.K. Upadhyaya. 2012. A mobile platform for measuring canopy photosynthetically active radiation interception in orchard systems. HortTechnology 22:237-244.

Lemay, I., J. Caron, M. Dorais, and S. Pepin. 2012. Defining irrigation set points based on substrate properties for variable irrigation and constant matric potential devices in greenhouse tomato. HortScience 47:1141-1152.

Lea-Cox, J.D. 2012. Using wireless sensor networks for precision irrigation scheduling, p. 233-258. In M. Kumar (ed.). Problems, perspectives and challenges of agricultural water management. InTech Press, Rijeka, Croatia.
Lichtenberg, E., J. Majsztrik, and M. Saavoss. 2013. Profitability of sensorbased irrigation in greenhouse and nursery crops. Hort Technology 23:770-774.

Löfkvist, K., R. Larsen, J.E. Englund, and B.W. Alsanius. 2009. Light integral as an indicator of water use in commercial greenhouse nurseries. Acta Agriculturae Scandinavica Sect. B-Soil Plant Sci. 59:326-334.

Majsztrik, J., E. Lichtenberg, and M. Saavoss. 2013. Ornamental grower perceptions of wireless irrigation sensor networks: Results from a national survey. HortTechnology 23:775-782.

McClymont, L., I. Goodwin, M. Mazza, N. Baker, D.M. Lanyon, A. Zerihun, S. Chandra, and M.O. Downey. 2012. Effect of site-specific irrigation management on grapevine yield and fruit quality attributes. Irr. Sci. 30:461-470.

Million, J.B., T.H. Yeager, and J.P. Albano. 2010. Evapotranspiration-based irrigation scheduling for container-grown Viburnum odoratissimum. HortScience 45:1741-1746.

Nemali, K.S., F. Montesano, S.K. Dove, and M.W. van Iersel. 2007. Calibration and performance of moisture sensors in soilless substrates: $\mathrm{ECH}_{2} \mathrm{O}$ and Theta probes. Sci. Hort. 112:227-234.

O'Meara, L., M.W. van Iersel, and M.R. Chappell. 2013. Daily water use of $\mathrm{Hy}$ drangea macrophylla and Gardenia jasminoides as affected by growth stage and environmental conditions. HortScience (In press).

Prehn, A.E., J.S. Owen, S.L. Warren, T.E. Bilderback, and J.P. Albano. 2010. Comparison of water management in container-grown nursery crops using leaching fraction or weight-based on demand irrigation control. J. Environ. Hort. 28:117-123.

Ross, D.S. 2008. Irrigation system design and components. In: J.D. Lea-Cox, D.S.
Ross, and C. Zhao (eds.). Green industry knowledge center for water and nutrient management learning modules. 12 Aug. 2013. <www.waternut.org/moodle/ course/view.php?id=19>.

Sager, J.C. and J.C. Mc Farlane. 1997. Radiation, p. 1-29. In: R.W. Langhans and T.W. Tibbits (eds.). Plant growth chamber handbook. Iowa Agr. Home Econ. Expt. Sta. Special Rpt. 99.

Scoggins, H.L. and M.W. van Iersel. 2006. In situ probes for measurement of EC of soilless substrates: Effects of temperature and substrate moisture content. HortScience 41:210-214.

Smith, S.H. 1962. Temperature correction in conductivity measurements. Limnol. Oceanogr. 7:330-334.

Strangeways, I. 2003. Measuring the natural environment. 2nd ed. Cambridge University Press.

Starry, O. 2013. The comparative effects of three Sedum species on green roof stormwater retention. Univ. Maryland, College Park, PhD Diss.

Tarara, J.M. and G.A. Hoheisel. 2007. Low-cost shielding to minimize radiation errors of temperature sensors in the field. HortScience 42:1372-1379.

van Iersel, M.W., S. Dove, J.G. Kang, and S.E. Burnett. 2010. Growth and water use of petunia as affected by substrate water content and daily light integral. HortScience 45:277-282.

van Iersel, M.W., S. Dove, and S.E. Burnett. 2011. The use of soil moisture probes for improved uniformity and irrigation control in greenhouses. Acta Hort. 893:1049-1056.

Wikipedia. 2013. Accuracy and precision. 27 Sept. 2013. <https://en.wikipedia.org/ wiki/Accuracy_and_precision $>$. 